\title{
A novel hospital capacity versus clinical justification triage score (CCTS) for prioritization of spinal surgeries in the "new normal state" of the COVID-19 pandemic
}

\author{
Gabriel Liu ${ }^{1}$ (1) Jun-Hao Tan ${ }^{1} \cdot$ Hwee Weng Dennis Hey ${ }^{1} \cdot$ Leok Lim Lau $^{1} \cdot$ Joseph Thambiah ${ }^{1} \cdot$ Naresh Kumar $^{1}$. \\ Jonathan Tan ${ }^{1}$ - John Ruiz ${ }^{1}$. Vincent Nga ${ }^{1}$. Sein Lwin ${ }^{1} \cdot$ Kejia Teo $^{1}$. Chou Ning ${ }^{1} \cdot$ Rohit Vijay Agrawal $^{1} \cdot$ Bryan NG $^{1}$. \\ Weng Hoa Wong ${ }^{1} \cdot$ Tseng Tsai Yeo $^{1} \cdot$ Hee-Kit Wong ${ }^{1}$
}

Received: 30 August 2020 / Revised: 8 November 2020 / Accepted: 22 November 2020 / Published online: 2 January 2021

(c) Springer-Verlag GmbH Germany, part of Springer Nature 2021

\begin{abstract}
Introduction During the Coronavirus disease 2019 outbreak, while healthcare systems and hospitals are diverting their resources to combat the pandemic, patients who require spinal surgeries continue to accumulate. The aim of this study is to describe a novel hospital capacity versus clinical justification triage score (CCTS) to prioritize patients who require surgery during the "new normal state" of the COVID-19 pandemic.

Methodology A consensus study using the Delphi technique was carried out among clinicians from the Orthopaedic Surgery, Neurosurgery, and Anaesthesia departments. Three rounds of consensus were carried out via survey and Webinar discussions. Results A 50-points score system consisting of 4 domains with 4 subdomains was formed. The CCTS were categorized into the hospital capacity, patient factors, disease severity, and surgery complexity domains. A score between 30 and 50 points indicated that the proposed operation should proceed without delay. A score of less than 20 indicates that the proposed operation should be postponed. A score between 20 and 29 indicates that the surgery falls within a grey area where further discussion should be undertaken to make a joint justification for approval of surgery.

Conclusion This study is a proof of concept for the novel CCTS scoring system to prioritize surgeries to meet the rapidly changing demands of the COVID-19 pandemic. It offers a simple and objective method to stratify patients who require surgery and allows these complex and difficult decisions to be unbiased and made transparently among surgeons and hospital administrators.
\end{abstract}

Keywords COVID-19 $\cdot$ Scoring system $\cdot$ Prioritization of surgery $\cdot$ Delphi technique $\cdot$ Resource utilization

\section{Introduction}

The coronavirus disease 2019 (COVID-19) has been declared as a global health emergency by the World Health Organization (WHO) on 11 March 2020 [1]. As of 22 June 2020, the WHO reported more than 8.8 million cases of COVID-19 infections globally, with approximately 460,000 deaths $[1,2]$. In this pandemic disease state, many healthcare systems and hospitals have cancelled their elective nonurgent surgical cases to divert resources for the management of the increasing number of COVID-19 patients [3, 4].

Gabriel Liu

Gabriel_LIU@nuhs.edu.sg

Extended author information available on the last page of the article
National Health Service (NHS) in United Kingdom defines obligatory in-patients (emergency patients) as those who continue to require surgical management, whom treatment should be expedited to avoid pre-operative delay. Urgent elective care was defined as patients with spinal conditions that may lead to neurological deterioration if not operated on in the near future, while routine elective care was defined as patients with stable spinal conditions that can continue conservative treatment. NHS recommends delaying all elective spinal surgery, and only emergent and urgent surgery should be performed [5]. Similarly, the American Academy of Orthopaedic Surgeons (AAOS) recommends their members to cancel all elective Orthopaedic surgeries [6], and the North American Spine Society (NASS) recommended that all elective spinal surgeries where spinal pain and dysfunction can be reasonably managed without surgical procedures 
should be postponed [7]. Based on NHS, AAOS, and NASS guidelines, Singapore Spine Society (SSS) defined emergency surgical conditions as unstable spinal fractures resulting from either trauma or pathological causes in patients with neurological deficits, cauda equina syndrome, or spinal infection, and has recommended that these cases should not be postponed despite the ongoing crisis [8]. The downstream effect of these changes is the accumulation of a large number of patients who require spinal surgery when COVID-19 measures ease.

The difficulty one anticipates after the COVID-19 outbreak stabilizes is the management of patients whose elective surgeries were postponed. While we should strive to provide timely treatment for these patients, one must be cognizant of the possibility of a second or even third wave of COVID-19 cases until a vaccine or herd immunity is attained [9]. A triage algorithm is needed to ensure patients who require surgery more urgently or less resource-dependent are prioritized, to allow the healthcare system to maintain its capacity for a rapid response against the surges in COVID-19 infections and the institute financial viability. The aim of this paper is to propose a generic scoring system for spine surgery triage to assist healthcare institutions and physicians'decision-making in prioritizing the large number of patients who require surgeries during the "new-normal state" of COVID-19.

\section{Methods}

A consensus study based on expert opinion using the Delphi method $[10,11]$ was performed in a university academic medical centre. Faculties from the orthopaedic surgery, neurosurgery, anaesthesia, surgical intensive care, and operating theatre (OT) committee were invited. After the study objectives, the structure of the scoring system, and initial parameters were determined by the lead author, the proposed system was refined using the Delphi method, spread across three rounds of analyses (Fig. 1). A detailed description of the Delphi process is found in the appendix of this paper.

\section{Results}

A total of 15 faculties participated in the Delphi process to devise the scoring system, of whom 8 were Orthopaedic Spine surgeons, 4 were Neurosurgery Spine surgeons, and 3 were Anaesthetists. Of the 3 Anaesthetists, one is the clinical director for the Anaesthesia department, one is the director for the Surgical Intensive Care Unit (SICU) and one is the chairman of the hospital Operative Theatre (OT) committee, who is in charge of the overall function of all operating theatre in the university hospital.

\section{Analysis of the survey}

In the initial phases, 17 subdomains and 63 factors were identified (Table 1). The faculties ranked each subdomain factors in isolation, with an average spread of the score on either end of the spectrum within each subdomain from a mean of $1.3 \pm 2.1$ to $9.7 \pm 0.4$. Table 2 shows the results of the average score ranking from the faculties on each factor.

Factors with a similar score were either regrouped as one factor, or removed from the scoring system. Subgroup analysis showed good concordance of ranking for surgery priority
Fig. 1 Flow chart showing refinement of the proposed system using the Delphi method

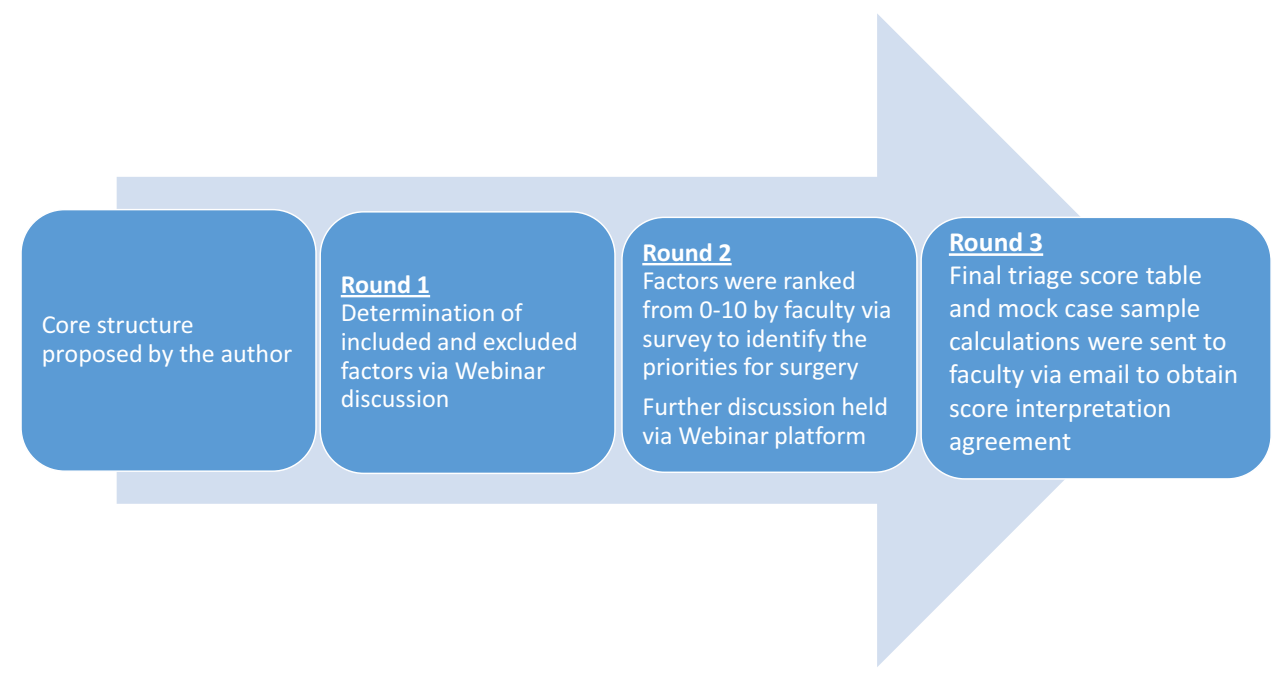


Table 1 Initial table (17 subdomains and 63 factors)

\begin{tabular}{|c|c|}
\hline Domains & Specific factors \\
\hline $\begin{array}{l}\text { Hospital capac- } \\
\text { ity domain }\end{array}$ & $\begin{array}{l}\text { Hospital equipment and space preparedness (Venti- } \\
\text { lators, PPE, beds, sterile equipment etc.) } \\
\text { Adequate preparedness } \\
\text { Moderate shortage } \\
\text { Acute shortage } \\
\text { Requires intensive monitoring post-operatively } \\
\text { General ward (GW) } \\
\text { High dependency unit (HD) } \\
\text { Intensive care unit (ICU) } \\
\text { Type of anaesthesia } \\
\text { Local (Regional) anaesthesia } \\
\text { General anaesthesia } \\
\text { Anticipated post-operative hospitalization stay } \\
\text { Day surgery (Discharge within office hours) } \\
\text { 23-h surgery } \\
\text { 1-3-day hospital stay } \\
\text { 4-6-day hospital stay } \\
\text { 27-day hospital stay }\end{array}$ \\
\hline $\begin{array}{l}\text { Patient factor } \\
\text { domain }\end{array}$ & $\begin{array}{l}\text { COVID-19 status } \\
\text { COVID-19 free (No prior exposure) } \\
\text { Recovered } \\
\text { Suspected } \\
\text { Confirmed (Asymptomatic) } \\
\text { Confirmed (Symptomatic) } \\
\text { Age } \\
11-64 \\
\leq 10 \\
\geq 65 \\
\text { Comorbidities } \\
\text { ASA } 1 \\
\text { ASA } 2 \\
\text { ASA } 3 \\
\text { ASA } 4 \\
\text { ASA } 5 \\
\text { Surgery waiting time } \\
>6 \text { months } \\
3-6 \text { months } \\
<3 \text { months } \\
\text { Surgery not postponed before } \\
\text { Number of times surgery had been postponed due } \\
\text { to COVID-19 } \\
\geq 3 \\
2 \\
1\end{array}$ \\
\hline
\end{tabular}

Table 1 (continued)

\begin{tabular}{|c|c|}
\hline Domains & Specific factors \\
\hline $\begin{array}{l}\text { Disease severity } \\
\text { domain }\end{array}$ & $\begin{array}{l}\text { Type of skeletal pathology } \\
\text { Fracture } \\
\text { Spinal metastasis and primary bone tumours } \\
\text { Spinal infections } \\
\text { Degenerative } \\
\text { Spinal deformity } \\
\text { Type of nerve pathology } \\
\text { Cauda equina syndrome } \\
\text { Cord compression (Myelopathy due to Extra- } \\
\text { dural lesion) } \\
\text { Intradural lesion } \\
\text { Radiculopathy } \\
\text { No neurological deficits } \\
\text { Severity of condition } \\
\text { Severe } \\
\text { Moderate } \\
\text { Mild } \\
\text { Pain score (VAS) } \\
\text { Severe: VAS 7-10 } \\
\text { Moderate: VAS 4-6 } \\
\text { Mild: VAS 1-3 }\end{array}$ \\
\hline $\begin{array}{l}\text { Surgery com- } \\
\text { plexity domain }\end{array}$ & $\begin{array}{l}\text { Surgical technique } \\
\text { Minimally invasive } \\
\text { Open } \\
\text { Revision surgery } \\
\text { Requiring osteotomy } \\
2 \text { stage surgery } \\
\text { Number of spinal segments involved } \\
1-2 \\
3-6 \\
\geq 7 \\
\text { Estimated operative duration } \\
<3 \mathrm{~h} \\
3-6 \mathrm{~h} \\
>6 \mathrm{~h} \\
\text { Potential blood transfusion (PCT) } \\
0 \\
1 \\
\geq 2\end{array}$ \\
\hline
\end{tabular}


of each factor among the faculties from Orthopaedic Surgery, Neurosurgery, and Anaesthesiology (Table 2). Spinal metastasis and primary bone tumour showed discordances ( $p$ value 0.010 ) between the surgeons and the anaesthetists.

\section{The final scoring system}

A scoring system, consisting of 4 domains with 4 subdomains and 49 subdomains based on patients' conditions and hospital resources was created to triage operation suitability to proceed for surgery during the COVID-19 pandemic.

The 4 domains were as follows (Table 3):
1) Hospital capacity
2) Patient factor
3) Disease severity
4) Surgery complexity

The hospital capacity domain consisted of 4 subdomains and its subdomain factors. The 4 subdomains were: Hospital and equipment preparedness, ward requirement for postoperative care, anticipated post-operative hospitalization stay duration, and type of anaesthesia required for surgery.

The patient factor domain consisted of 4 subdomains and its subdomain factors. The 4 subdomains were: The patient'sCOVID-19 status, patient's comorbidities classified by the American Society of Anaesthesiologist (ASA) [12] classification, surgery waiting time, and the number of times the patient's surgery has been cancelled due to lack of hospital resources during the COVID-19 pandemic.

The disease severity domain consists of 4 subdomains and its subdomain factors. The 4 subdomains were: Type of pathology, type of nerve deficit, severity of the condition, and pain score using the visual analogue score (VAS) [13]. To ensure that the severity of the disease is classified objectively, existing and well-validated scoring systems are referenced in the score table, depending on the type of spinal pathology to aid in decision-making. These include the thoracolumbar injury classification score (TLICS) [14] for spinal fractures, American Spinal Injury Association (ASIA) [15] classification for spinal cord injuries, Japan Orthopaedic Association (JOA) [16] score for cervical myelopathy, spinal instability neoplastic score (SINS) [17] for metastatic spinal disease, and patient outcome scores such as the Neck Disability Index (NDI) [18] and Oswestry Disability Index (ODI) [19]for spinal disorders were utilized. The cut-offs for each score representing severe, moderate, and mild disease were reported in Table 3 . The exception to this severity grading is that of patients with early-onset scoliosis, where treatment is time-sensitive and delay of treatment may result in cardiopulmonary compromise and increased mortality [20,
21]. For this reason, patients with EOS were categorized as severe under the disease severity subdomain.

The surgery complexity domain consists of 4 subdomains and its subdomain factor-groups. The 4 subdomains were: Surgical technique complexity, number of spinal segments involved, estimated operation duration, and potential blood transfusion required. Table 3 shows the details of the individual subdomain factors.

A trial of mock calculation using the score table on various patient scenarios was performed, and increases in weightage of certain subdomain factors were made to meet the faculties' consensus and recommendations by the various societies and guidelines. A 300\% increase in weightage in the subdomain factors in hospital and equipment preparedness, type of pathology, type of nerve deficit, and severity of the condition was made. A total of 50 points were created for the scoring system. The average surgical score obtained from the hypothetical patient scenarios during an acute hospital capacity shortage state for cauda equina syndrome, unstable spinal fractures, single-level cervical myelopathy, lumbar prolapsed intervertebral disc, lumbar spondylolisthesis, adult or children deformity without neurological deficits were calculated as 33, 32, 28, 25, 20, 11 and 9 points, respectively (Table 4, Fig. 2). The estimated score for a patient with EOS was 20 points.

\section{Interpretation of scores}

A score of 30-50 obtained from Table 3 indicates that the surgery is of the emergency or high priority category and the proposed operation should proceed without delay, even during the state of acute shortage of hospital capacity. These include patients suffering from cauda equina syndrome, unstable spine fractures with cord injury, and spinal infection (Table 4, Fig. 2). A score of less than 20 would indicate that the surgery is not urgent but of an elective nature with a high resource burden, and the proposed operation should be postponed until hospital capacity returns to normal. These include patients with adult or paediatric spinal deformity without neurological deficits. A score of 20-29 indicates a grey area, where further discussion between various spine consultants, the chief of the division, or the Operating Theatre (OT) committee should be undertaken to make a joint justification for approval of surgery during the state of acute hospital resource shortage. These include patients suffering from cervical myelopathy, lumbar prolapsed intervertebral disc, or degenerative lumbar disease with significant neurological deficits such as patients with acute foot drop. The score obtained from Table 3 would increase as hospital capacity returns to normal. A higher score indicates a higher priority for the proposed surgery to proceed. This interpretation of the score obtained a $100 \%$ agreement among all the faculties in the study. 
Table 2 Mean scores of collated responses by experts

\begin{tabular}{|c|c|c|c|c|c|}
\hline Specific factors & Mean & Mean NES & Mean ortho & Mean anaes & $p$ value \\
\hline \multicolumn{6}{|c|}{ Hospital equipment and space preparedness (Ventilators, PPE, sterile equipment etc.) } \\
\hline Adequate preparedness & $9(8-10)$ & $9.3(8-10)$ & $10.0(10)$ & $9.3(8-10)$ & 0.162 \\
\hline Moderate shortage & $5.5(1-9)$ & $5.3(1-9)$ & $5.6(1-8)$ & $5.7(3-9)$ & 0.974 \\
\hline Acute shortage & $2.6(1-8)$ & $2.0(1-8)$ & $2.5(1-5)$ & $1.3(1-2)$ & 0.231 \\
\hline \multicolumn{6}{|l|}{ Requires intensive monitoring post-operatively } \\
\hline General ward (GW) & $9.5(5-10)$ & $9.8(9-10)$ & $9.8(8-10)$ & $8.3(5-10)$ & 0.331 \\
\hline High dependency Unit (HD) & $6.1(4-10)$ & $6.3(5-9)$ & $5.8(4-10)$ & $7.0(5-8)$ & 0.549 \\
\hline Intensive Care Unit (ICU) & $2.9(1-8)$ & $2.8(1-5)$ & $3.0(1-8)$ & $2.7(1-5)$ & 0.971 \\
\hline \multicolumn{6}{|l|}{ Type of anaesthesia } \\
\hline Local (Regional) anaesthesia & $7.5(2-10)$ & $8.0(7-9)$ & $7.5(2-10)$ & $10(10)$ & 0.311 \\
\hline General anaesthesia & $5.7(1-10)$ & $7.0(5-8)$ & $5.1(1-10)$ & $5.3(4-7)$ & 0.514 \\
\hline \multicolumn{6}{|l|}{ Anticipated post-operative hospitalization stay } \\
\hline Day surgery (Discharge within office hours) & $9.6(4-10)$ & $9.3(8-10)$ & $9.6(4-10)$ & $10.0(10)$ & 0.621 \\
\hline 23-h surgery & $8.6(6-10)$ & $8.5(8-10)$ & $8.8(6-10)$ & $8.3(7-10)$ & 0.986 \\
\hline 1-3-day hospital stay & $5.6(2-9)$ & $5.3(2-8)$ & $5.8(2-9)$ & $5.3(5-6)$ & 0.790 \\
\hline 4-6-day hospital stay & $4.4(2-8)$ & $5.3(4-7)$ & $4.0(2-8)$ & $4.3(3-5)$ & 0.742 \\
\hline$\geq 7$-day hospital stay & $2.6(1-7)$ & $2.3(1-5)$ & $2.5(1-7)$ & $3.3(1-5)$ & 0.799 \\
\hline \multicolumn{6}{|l|}{ COVID-19 status } \\
\hline COVID-19 free (No prior exposure) & $9.1(1-10)$ & $9.5(1-10)$ & $8.6(1-10)$ & $10.0(10)$ & 0.679 \\
\hline Recovered & $7.9(3-10)$ & $7.8(5-10)$ & $7.8(3-10)$ & $8.3(5-10)$ & 0.943 \\
\hline Suspected & $3.9(1-10)$ & $3.3(1-10)$ & $4.3(1-8)$ & $4.0(1-6)$ & 0.700 \\
\hline Confirmed (Asymptomatic) & $3.2(1-10)$ & $1.8(1-10)$ & $4.0(1-10)$ & $3.0(1-7)$ & 0.690 \\
\hline Confirmed (Symptomatic) & $3.0(1-10)$ & $1.5(1-10)$ & $3.6(1-10)$ & $3.3(1-8)$ & 0.699 \\
\hline \multicolumn{6}{|l|}{ Age } \\
\hline $11-64$ & $7.3(3-10)$ & $6.8(5-10)$ & $7.4(3-10)$ & $8.0(5-10)$ & 0.755 \\
\hline$\leq 10$ & $5.5(1-10)$ & $5.3(1-8)$ & $4.6(1-10)$ & $8.0(5-10)$ & 0.314 \\
\hline$\geq 65$ & $4.8(1-9)$ & $5.0(5)$ & $4.4(1-9)$ & $5.7(3-9)$ & 0.929 \\
\hline \multicolumn{6}{|l|}{ Comorbidities } \\
\hline ASA 1 & $9.5(1-10)$ & $9.5(8-10)$ & $9.9(1-10)$ & $8.3(5-10)$ & 0.911 \\
\hline ASA 2 & $8.1(1-10)$ & $6.8(4-9)$ & $8.8(1-10)$ & $8.0(5-10)$ & 0.809 \\
\hline ASA 3 & $5.3(1-10)$ & $5.5(4-9)$ & $4.6(1-8)$ & $7.0(5-10)$ & 0.298 \\
\hline ASA 4 & $3.0(1-10)$ & $3.0(1-8)$ & $2.6(1-10)$ & $4.0(1-9)$ & 0.990 \\
\hline ASA $5 \geq 3$ & $1.3(1-10)$ & $1.3(1-8)$ & $1.5(1-10)$ & $4.0(1-10)$ & 0.697 \\
\hline \multicolumn{6}{|l|}{ Surgery waiting time } \\
\hline$>6$ months & $7.9(2-10)$ & $8.5(5-9)$ & $7.5(2-10)$ & $6.3(5-9)$ & 0.852 \\
\hline $3-6$ months & $5.6(1-10)$ & $6.0(5-8)$ & $5.5(1-10)$ & $5.3(4-7)$ & 0.781 \\
\hline$<3$ months & $3.1(1-5)$ & $4.3(1-5)$ & $2.8(1-5)$ & $2.3(1-5)$ & 0.270 \\
\hline \multicolumn{6}{|c|}{ Number of times surgery had been postponed due to COVID-19 } \\
\hline$\geq 3$ & $7.7(1-10)$ & $8.8(8-10)$ & $8.1(1-10)$ & $5.0(2-10)$ & 0.264 \\
\hline 2 & $5.6(1-10)$ & $6.5(4-8)$ & $6.1(1-10)$ & $2.3(1-5)$ & 0.107 \\
\hline 1 & $3.4(1-10)$ & $4.0(2-7)$ & $2.8(1-5)$ & $5.3(1-10)$ & 0.313 \\
\hline \multicolumn{6}{|l|}{ Type of skeletal pathology } \\
\hline Unstable fracture & $9.3(8-10)$ & $9.8(9-10)$ & $9.4(8-10)$ & $8.7(8-10)$ & 0.304 \\
\hline Spinal metastasis and primary bone tumours & $9.7(5-10)$ & $9.8(9-10)$ & $10.0(10)$ & $8.7(8-10)$ & $0.010^{*}$ \\
\hline Spinal infections & $9.2(7-10)$ & $9.8(9-10)$ & $9.3(7-10)$ & $8.3(7-10)$ & 0.284 \\
\hline Degenerative & $4.3(1-8)$ & $4.8(3-8)$ & $4.5(2-7)$ & 3. $0(1-6)$ & 0.526 \\
\hline Spinal deformity & $3.7(1-10)$ & $4.0(2-6)$ & $3.8(2-6)$ & $5.7(1-10)$ & 0.485 \\
\hline \multicolumn{6}{|l|}{ Type of nerve pathology } \\
\hline Cauda equina syndrome & $9.9(8-10)$ & $9.5(8-10)$ & $10.0(10)$ & $10.0(10)$ & 0.269 \\
\hline
\end{tabular}


Table 2 (continued)

\begin{tabular}{|c|c|c|c|c|c|}
\hline Specific factors & Mean & Mean NES & Mean ortho & Mean anaes & $p$ value \\
\hline $\begin{array}{l}\text { Cord compression (Myelopathy due to Extra-dural } \\
\text { lesion) }\end{array}$ & $9.7(7-10)$ & $9.8(9-10)$ & $9.3(7-10)$ & $8.7(7-10)$ & 0.467 \\
\hline Intradural lesion & $7.8(5-10)$ & $8.3(7-10)$ & $8.1(6-10)$ & $6.3(5-8)$ & 0.199 \\
\hline Radiculopathy & $4.7(1-8)$ & $5.3(3-8)$ & $4.4(1-8)$ & $4.7(3-6)$ & 0.657 \\
\hline No neurological deficits & $1.9(1-10)$ & $3.0(2-5)$ & $1.6(1-4)$ & $5.0(1-10)$ & 0.163 \\
\hline \multicolumn{6}{|l|}{ Severity of condition } \\
\hline Severe & $9.4(5-10)$ & $9.8(9-10)$ & $9.4(8-10)$ & $8.3(5-10)$ & 0.418 \\
\hline Moderate & $5.8(1-9)$ & $6.8(5-9)$ & $5.6(5-8)$ & $3.7(1-5)$ & 0.090 \\
\hline Mild & $2.3(1-6)$ & $3.0(1-6)$ & $1.8(1-4)$ & $3.7(1-5)$ & 0.227 \\
\hline \multicolumn{6}{|l|}{ Pain score (VAS) } \\
\hline Severe: VAS 7-10 & $7.7(3-10)$ & $8.5(7-10)$ & $7.8(3-10)$ & $6.0(5-7)$ & 0.290 \\
\hline Moderate: VAS 4-6 & $5.1(2-10)$ & $6.0(5-7)$ & $4.8(2-9)$ & $7.0(5-10)$ & 0.314 \\
\hline Mild: VAS 1-3 & $2.1(1-5)$ & $2.8(1-6)$ & $1.9(1-5)$ & $2.0(1-4)$ & 0.662 \\
\hline \multicolumn{6}{|l|}{ Surgical technique } \\
\hline Minimally invasive & $6.5(1-10)$ & $5.5(3-8)$ & $6.5(1-10)$ & $7.7(3-10)$ & 0.696 \\
\hline Open & $5.9(1-9)$ & $6.3(3-9)$ & $6.0(1-8)$ & $4.7(1-8)$ & 0.780 \\
\hline Revision surgery & $4.7(1-9)$ & $6.3(8-10)$ & $4.1(1-8)$ & $4.0(3-5)$ & 0.350 \\
\hline Requiring osteotomy & $3.8(1-9)$ & $5.5(3-9)$ & $2.9(1-5)$ & $4.0(2-5)$ & 0.172 \\
\hline 2 stage surgery & $3.7(1-9)$ & $6.8(5-9)$ & $2.9(1-8)$ & $3.7(1-7)$ & 0.108 \\
\hline \multicolumn{6}{|l|}{ Number of spinal segments involved } \\
\hline $1-2$ & $8.1(1-10)$ & $7.8(5-9)$ & $7.9(1-10)$ & $9.3(8-10)$ & 0.451 \\
\hline $3-6$ & $5.6(1-10)$ & $5.5(4-10)$ & $5.6(1-9)$ & $5.7(5-6)$ & 0.666 \\
\hline$\geq 7$ & $3.4(1-10)$ & $3.3(2-10)$ & $3.3(1-7)$ & $4.3(1-8)$ & 0.690 \\
\hline \multicolumn{6}{|l|}{ Estimated operative duration } \\
\hline$<3 \mathrm{~h}$ & $9.1(1-10)$ & $8.5(4-9)$ & $9.1(1-10)$ & $10.0(10)$ & 0.421 \\
\hline $3-6 \mathrm{~h}$ & $6.2(5-9)$ & $5.8(5-9)$ & $6.5(5-8)$ & $6.0(5-8)$ & 0.816 \\
\hline$>6 \mathrm{~h}$ & $4.1(1-10)$ & $3.5(2-10)$ & $3.9(1-10)$ & $6.7(5-9)$ & 0.666 \\
\hline \multicolumn{6}{|l|}{ Potential blood transfusion (PCT) } \\
\hline 0 & $9.2(1-10)$ & $8.8(2-10)$ & $9.1(1-10)$ & $8.3(5-10)$ & 0.411 \\
\hline 1 & $6.3(2-9)$ & $6.5(4-9)$ & $6.5(2-9)$ & $4.3(3-5)$ & 0.378 \\
\hline$\geq 2$ & $2.7(1-10)$ & $3.3(4-10)$ & $2.9(1-10)$ & $5.3(1-10)$ & 0.261 \\
\hline
\end{tabular}

Values are presented as mean (Range)

${ }^{*} p$ values $<0.05$, indicating that there was a statistically significant difference between groups

\section{Discussion}

The "flattening the curve" approach using early infection detection, social distancing, and isolation has been the strategy of choice to reduce mortality rates from the COVID-19 pandemic [22]. Higher COVID-19 mortality rates were seen when healthcare systems unable to support the high numbers of COVID-19 patients [23, 24]. As the hospitals' capacity was stretched to the limit, all elective surgeries were cancelled to preserve its resource capacity. This has led to a downstream effect of a large backlog of patients who requires elective surgeries when the COVID19 measures ease. Using a susceptible-infectious-recovered model, Leung et al. [25] predicted a possible second wave of COVID-19 infections. It is hence evident that when countries manage to control their first wave of COVID-19 infections, one must anticipate and place measures in place to ensure the hospitals' capacity will be able to tackle a possible second or third wave of COVID-19 infections until a vaccine is available or herd immunity occurs [9].

In this study, we proposed a 50-point triage system, with 4 domains, 4 subdomains, and 49 subdomain factors to triage the priority for patients' spinal surgery and objectively match the hospital resource allocations. This allows for the often complex and difficult decision of assessing the relative importance of different patients to be transparent and unbiased among surgeons, hospital administrators, and patients. It provides the evaluation of factors including operating theatre constraints, resource requirements for post-operative patient care, and the number of times the patients' surgery 
Table 3 Final hospital capacity versus clinical justification triage score (CCTS)

\begin{tabular}{ll}
\hline Domains & Subdomains \\
\hline Hospital capacity domain & Hospital preparedness and equipment* \\
& Ward requirement for post-operative care \\
& Anticipated post-operative hospitalization stay
\end{tabular}

Type of anaesthesia

Total score for hospital capacity domain

COVID-19 status

Comorbidities

Surgery waiting time

Number of times surgery had been postponed due to COVID-19

Score

Total score for patient factor domain

Disease severity domain
Type of pathology

Type of nerve deficit

Severity of condition $* * * *$

Pain score (VAS)

Total score for disease severity domain

Surgery complexity domain
Surgical technique complexity
COVID-19 infection confirmed

ASA 1 and 2

ASA 3 and 4

ASA 5

$>6$ months

3-6 months

$<3$ months

$\geq 2$

1

0

Moderate shortage ${ }^{\mathrm{b}}$

General ward (GW)

High dependency unit (HD)

Intensive care unit (ICU)

$\geq 7$-day hospital stay

Local anaesthesia

General anaesthesia

COVID-19 free (No prior exposure) or recovered 2

3

0

2

1

0

2

1

0

2

0

0

2

1

0

2

1

0

2

1

0

/8

Unstable spinal fracture (Traumatic, metastatic or 8 infective)***Epidural abscess cauda equina syndrome

Primary bone tumours Intra-dural lesions 6

Rapid progressing deformity 4

Stable degenerative spine (Cervical, thoracic and thora- 2 columbar junction)

Stable degenerative spine(Lumbar) $\quad 0$

Symptomatic cord compression (or myelopathy) 6

Symptomatic nerve root compression (or neurogenic 3 claudication)

No neurological deficits 0

Severe 6

Moderate 3

Mild 0

Severe: VAS 7-10 2

Moderate: VAS 4-6 1

Mild: VAS 1-3 0

122

Low(Discectomy, decompression without fusion, verte- $\quad 2$ broplasty, kyphoplasty)

Moderate(TLIF, Laminectomy and fusion, LLIF, ALIF, 1 $A C D F, A C C F$, Laminoplasty) 
Table 3 (continued)

\begin{tabular}{|c|c|c|c|}
\hline Domains & Subdomains & Factors & Score \\
\hline & & $\begin{array}{l}\text { High(Requiring osteotomy, Deformity corrective surgery, } \\
\text { Complex revision surgery, Staged surgery) }\end{array}$ & 0 \\
\hline & Number of spinal segments involved & $1-2$ & 2 \\
\hline & & $3-6$ & 1 \\
\hline & & $\geq 7$ & 0 \\
\hline & Estimated operation duration & $<2 \mathrm{~h}$ & 2 \\
\hline & & $2-5 \mathrm{~h}$ & 1 \\
\hline & & $>5 \mathrm{~h}$ & 0 \\
\hline & Potential blood transfusion (PCT) & 0 & 2 \\
\hline & & 1 & 1 \\
\hline & & $\geq 2$ & 0 \\
\hline Total score for surgical complexity domain & & & 18 \\
\hline Total score & & & 150 \\
\hline \multicolumn{4}{|l|}{ Interpretation of scores } \\
\hline$<20$ & Recommend to defer surgery & & \\
\hline \multirow[t]{2}{*}{$20-29$} & Recommend to consider for surgery & & \\
\hline & $\begin{array}{l}\text { Suggest involvement and discussion b } \\
\text { committee to make a joint decision }\end{array}$ & $\begin{array}{l}\text { altants, chief of division, } H O D \text { and or Operating theatre (OT } \\
\text { al }\end{array}$ & \\
\hline
\end{tabular}

${ }^{a}$ Acute shortage: Equivalent to Dorscon Red in Singapore (https://www.gov.sg/article/what-do-the-different-dorscon-levels-mean. What do the different DORSCON levels mean. Assessed on 15/5/2020 6/2/2020.), Incident Level 4 in UK (https://www.england.nhs.uk/wp-content/uploa ds/2017/07/NHS-england-incident-response-plan-v3-0.pdf. NHS England Emergency Preparedness, Resilience and Response Incident Response Plan (National). Accessed on 15/5/2020 July 2017), Global Health Advisory level 4 in USA (US Department of State BoCA. Global Level 4 Health Advisory-Do Not Travel. https://travel.state.gov/content/travel/en/traveladvisories/ea/travel-advisory-alert-global-level-4-health-advisory-issue.htm 2020;Accessed on 22/5/2020).

${ }^{\mathrm{b}}$ Moderate shortage: Equivalent to Dorscon Orange in Singapore (https://www.gov.sg/article/what-do-the-different-dorscon-levels-mean. What do the different DORSCON levels mean. Accessed on 15/5/2020 6/2/2020.), Incident Level 3 in UK (https://www.england.nhs.uk/wp-conte nt/uploads/2017/07/NHS-england-incident-response-plan-v3-0.pdf. NHS England Emergency Preparedness, Resilience and Response Incident Response Plan (National). Assessed on 15/5/2020 July 2017), Global Health Advisory level 3 in USA (US Department of State BoCA. Global Level 4 Health Advisory-Do Not Travel. https://travel.state.gov/content/travel/en/traveladvisories/ea/travel-advisory-alert-global-level-4-healthadvisory-issue.html 2020;Accessed on 22/5/2020).

${ }^{\mathrm{c}}$ Adequate preparedness: Equivalent to Dorscon Green/ Yellow in Singapore (https://www.gov.sg/article/what-do-the-different-dorscon-level s-mean. What do the different DORSCON levels mean. Accessed on 15/5/2020 6/2/2020.), Incident Level 1/2 in UK (https://www.engla nd.nhs.uk/wp-content/uploads/2017/07/NHS-england-incident-response-plan-v3-0.pdf. NHS England Emergency Preparedness, Resilience and Response Incident Response Plan (National). Assessed on 15/5/2020 July 2017), Global Health Advisory level 1/2 in USA (US Department of State BoCA. Global Level 4 Health Advisory-Do Not Travel. https://travel.state.gov/content/travel/en/traveladvisories/ea/travel-advisory-alertglobal-level-4-health-advisory-issue.html2020;Accessed on 22/5/2020).

${ }^{*}$ Equipment such as ventilators, personal protective equipment (PPE), ICU/ hospital beds etc.

${ }^{* * *}$ Day surgery: Stay $\leq 4$ h, 23-h surgery: Stay $\leq 23$ h

${ }^{* * * *}$ Stable spinal fractures, stable metastasis, osteomyelitis or spondylodisciitis are scored as stable degenerative spine conditions

${ }^{* * * * *}$ Severity grading depends on disease-specific scores

Traumatic spinal fractures (TLICS score): Mild 0-3, Moderate: 4, Severe: $\geq 4$ ASIA impairment scale: Mild: Grade D/ E, Moderate: Grade C/ B, Severe: Grade: A ODI: Mild <20\%, Moderate: $21-40 \%$, Severe: $>41-60 \%$ Cervical Myelopathy (JOA score): Mild: $\geq 15$, Moderate: $12-14$, Severe: $<12$ Neck pain NDI: Mild $<30 \%$, Moderate: $30-49 \%$, Severe: $\geq 50 \%$ Spinal metastasis (SINS score): Mild: 0-6, Moderate 7-12, Severe: 13-18Spinal deformity: Mild $<50^{\circ}$, Moderate: $50-70^{\circ}$, Severe $>70^{\circ}$ (Exception: Early onset-scoliosis)

Central canal stenosis: Mild: Ligamentumflavum hypertrophy or osteophytes or disk bulging without narrowing of the central spinal canal, Moderate: Central spinal canal is narrowed but spinal fluid is still clearly visible between the nerve roots in the dural sac, Severe: Central spinal canal is narrowed and there is only a faint amount of spinal fluid or no fluid between the nerve roots in the dural sac

Foraminal stenosis: Mild: No stenosis, normal peri-neural fat, Moderate: Slight stenosis with compression of perineural fat, Severe: Loss of perineural fat 
had been cancelled due to lack of hospital capacity to be reviewed, which were otherwise not considered in the established disease severity classification. Furthermore, the separation of providing care and making difficult triage decisions by the clinician can significantly reduce physician burnout and moral injury [3, 26, 27]. In the Médecins Sans Frontières organization, guidelines and recommendations exist to assist surgeons in prioritization during wartime surgery, in the face of limited resources [28]. During the COVID-19 pandemic, Prachand et al. [29] described a generalized 5-point scale scoring system to assist in decision-making for all types of surgeries [3], which may not be suitable for use to triage the multitude of factors needed for considerations in spinal surgery.

The hospital capacity domain in the scoring system is a surrogate marker for whether the hospital has enough capacity to support elective surgeries. Factors such as anticipated duration of hospitalization stay, intensive care unit (ICU) stay, and the adequacy of hospital equipment will determine if the hospital can support the additional burden of an elective surgical patient places on the healthcare system, potentially risking the diversion of scarce resources away from COVID-19 patients. In Italy, when the public health needs for COVID-19 patients have exceeded the capabilities of the healthcare systems, the Italian Society of Anaesthesia Analgesia Resuscitation and Intensive Care (SIAARTI) has published recommendations and ethical considerations to aid physicians in the decision-making process of prioritization [30]. In Australia, it has been reported that a maximal surge of COVID-19 cases would require an increase of $191 \%$ in ICU beds, $120 \%$ increase in invasive ventilators, $245 \%$ increase in senior doctors, and $269 \%$ increase in ICU nurses [31]. The incorporation of the hospital capacity domain to monitor the hospital equipment resources, ICU availability, hospital beds and ventilators in general anaesthesia requirements allow for flexibility in this triage system to meet the needs of this fluid state of COVID-19 situation.

The patient factors domain was designed to assess the overall risk profile of a patient for complications arising from spinal surgery and the duration that the patient has endured while waiting for surgical intervention. Patients' comorbidities have been reported as risk factors for postoperative complications arising from a variety of spinal surgeries [32-35]. We used the American Society of Anaesthesiologists (ASA) classification, a well-validated simple tool, to assess the patients' comorbidities. It has been reported that a higher ASA grade predicts increased post-operative revision surgeries, length of hospitalization stay, wound complications, cardio-respiratory complications, and mortality, which in turn translates to an increased strain on the hospitals' resources [36]. Surgery waiting time, the number of times surgery has been postponed due to the pandemic, and the patient's COVID status should be taken into consideration as well. This is similar to the situation in organ transplantations, where these factors come into play for decision-making and surgical waiting time should be accounted for in prioritization of surgery [37, 38].

The disease severity domain is the most important consideration in determining the priority of surgery. It carries the highest weightage in the CCTS to provide the differentiating power required to meet the recommendations set by the established international academic societies and the consensus obtained by the faculties in the study. Due to the impracticality to include all published spinal disease-specific score system into the CCTS, we designed the disease severity domain in the CCTS to be broad-based with subdomain categories as the type of spinal pathology, nerve deficit, the severity of condition and pain score. The severity of the condition subdomain was categorized into mild, moderate, and severe which was intentionally kept open to interpretation by the user and based on the surgeon's clinical judgment. Validated scoring systems that define the severity of disease were enclosed as an appendix and were recommended to be utilized in conjunction with the CCTS to avoid subjectivity. These include the thoracolumbar injury classification system (TLICS) [14], spinal instability neoplastic score (SINS) score [17], Japanese Orthopaedic Association (JOA) score [16], MRI grading systems for central canal [39] and foraminal stenosis [40], Cobb angles, Neck disability index (NDI) [18], and Oswestry disability index (ODI) [19]. The visual analogue score (VAS) pain score was incorporated for pain subdomain in our score [13], as Matamalas reported that patient-reported pain score was a predominant driving force for patients to demand for surgery [41].

The surgical complexity domain was designed to include factors of surgical technique, number of spinal segments involved in surgery, the estimated operation time, and the potential need for post-operative blood transfusion. The complexity of surgery reflects the potential risk of patients developing intra-and post-operative complications, which in turn requires additional hospital resources. Horn et al. [42] reported that with an increased number of spinal levels involved and longer duration of surgery, there is an increased risk of intra- and post-operative complications, leading to increased clinical and economic burden to the hospital. This increased inpatients' hospitalization and ICU stay put further strain on the scarce resources of the hospital. Blood transfusion requirement is another important consideration. In addition to the fact that blood donation and supplies have dwindled during the COVID-19 pandemic, Hu et al. [43] reported in a meta-analysis that patients requiring blood transfusion had a 3 times increase in the risk of developing post-operative infection after spinal surgery.

One of the limitations of the scoring system is that the weightage of various factors, in theory, might be different in reality. As this is a proof of concept study, future studies would 
Table 4 Average surgical score obtained from the hypothetical patient scenarios

\begin{tabular}{|c|c|c|c|}
\hline Cases & Score (No shortage) & Score (No shortage) & Score (severe shortage) \\
\hline Case 1 & Hospital: $6+2+1+0$ & Hospital: $3+2+1+0$ & Hospital: $0+2+1+0$ \\
\hline \multirow{4}{*}{$\begin{array}{l}\text { 40-year-old cauda equina syn- } \\
\text { drome }\end{array}$} & Patient: $2+2+0+0$ & Patient: $2+2+0+0$ & Patient: $2+2+0+0$ \\
\hline & Disease: $8+3+6+1$ & Disease: $8+3+6+1$ & Disease: $8+3+6+1$ \\
\hline & Complexity: $2+2+2+2$ & Complexity: $2+2+2+2$ & Complexity: $2+2+2+2$ \\
\hline & Total: 39 & Total: 36 & Total: 33 \\
\hline \multirow[t]{2}{*}{ Case 2} & Hospital: $6+1+1+0$ & Hospital: $3+1+1+0$ & Hospital: $0+1+1+0$ \\
\hline & Patient: $2+2+0+0$ & Patient: $2+2+0+0$ & Patient: $2+2+0+0$ \\
\hline 40 year old & Disease: $8+6+6+2$ & Disease: $8+6+6+2$ & Disease: $8+6+6+2$ \\
\hline ASIA C & Complexity: $1+1+1+1$ & Complexity: $1+1+1+1$ & Complexity: $1+1+1+1$ \\
\hline Unstable T12 burst fracture & Total: 38 & Total: 35 & Total: 32 \\
\hline Case 3 & Hospital: $6+1+1+0$ & Hospital: $3+1+1+0$ & Hospital: $0+1+1+0$ \\
\hline 65 year old with severe & Patient: $2+1+1+0$ & Patient: $2+1+1+0$ & Patient: $2+1+1+0$ \\
\hline Cervical myelopathy & Disease: $2+6+6+1$ & Disease: $2+6+6+1$ & Disease: $2+6+6+1$ \\
\hline \multirow[t]{2}{*}{ ACDF: 1 level } & Complexity: $1+2+2+2$ & Complexity: $1+2+2+2$ & Complexity: $1+2+2+2$ \\
\hline & Total: 34 & Total: 31 & Total: 28 \\
\hline 65 year old with severe & Hospital: $6+1+1+0$ & Hospital: $3+1+1+0$ & Hospital: $0+1+1+0$ \\
\hline Cervical myelopathy & Patient: $2+1+1+0$ & Patient: $2+1+1+0$ & Patient: $2+1+1+0$ \\
\hline \multirow[t]{3}{*}{ Laminoplasty: 5 levels } & Disease: $2+6+6+1$ & Disease: $2+6+6+1$ & Disease: $2+6+6+1$ \\
\hline & Complexity: $1+1+1+2$ & Complexity: $1+1+1+2$ & Complexity: $1+1+1+2$ \\
\hline & Total: 32 & Total: 29 & Total: 26 \\
\hline Case 4 & Hospital: $6+2+2+0$ & Hospital: $3+2+2+0$ & Hospital: $0+2+2+0$ \\
\hline \multirow{4}{*}{$\begin{array}{l}30 \text { year old with L5 radiculopa- } \\
\text { thy and pain from L4/5 PID } \\
\text { (prolapsed intervertebral disc) }\end{array}$} & Patient: $2+2+1+0$ & Patient: $2+2+1+0$ & Patient: $2+2+1+0$ \\
\hline & Disease: $0+3+3+2$ & Disease: $0+3+3+2$ & Disease: $0+3+3+2$ \\
\hline & Complexity: $2+2+2+2$ & Complexity: $2+2+2+2$ & Complexity: $2+2+2+2$ \\
\hline & Total: 31 & Total: 28 & Total: 25 \\
\hline Case 5 & Hospital: $6+2+2+2$ & Hospital: $3+2+2+2$ & Hospital: $0+2+2+2$ \\
\hline \multirow{4}{*}{$\begin{array}{l}75 \text { year old for T12 level Verte- } \\
\text { broplasty }\end{array}$} & Patient: $2+1+0+0$ & Patient: $2+1+0+0$ & Patient: $2+1+1+0$ \\
\hline & Disease: $0+0+3+1$ & Disease: $0+0+3+1$ & Disease: $1+0+6+2$ \\
\hline & Complexity: $2+2+2+2$ & Complexity: $2+2+2+2$ & Complexity: $2+2+2+2$ \\
\hline & Total: 33 & Total: 30 & Total: 27 \\
\hline Case 6 & Single-level TLIF & Single-level TLIF & Single-level TLIF \\
\hline $\begin{array}{l}65 \text { year old with mild L5 weak- } \\
\text { ness and pain }\end{array}$ & Hospital: $6+2+1+0$ & Hospital: $3+2+1+0$ & Hospital: $0+2+1+0$ \\
\hline \multirow{4}{*}{$\begin{array}{l}\text { (A) L4/5 grade } 1 \text { listhesis with } \\
\text { stenosis ( } 1 \text { level TLIF) }\end{array}$} & Patient: $2+1+1+0$ & Patient: $2+1+1+0$ & Patient: $2+1+1+0$ \\
\hline & Disease: $0+3+3+1$ & Disease: $0+3+3+1$ & Disease: $0+3+3+1$ \\
\hline & Complexity: $1+2+1+2$ & Complexity: $1+2+1+2$ & Complexity: $1+2+1+2$ \\
\hline & Total: 26 & Total: 23 & Total: 20 \\
\hline \multirow{5}{*}{$\begin{array}{l}\text { (B) L4/5, L5/S1 grade } 1 \\
\text { listhesis with stenosis ( } 2 \text { level } \\
\text { TLIF) }\end{array}$} & 2 level TLIF & 2 level TLIF & 2 level TLIF \\
\hline & Hospital: $6+1+1+0$ & Hospital: $3+1+1+0$ & Hospital: $0+1+1+0$ \\
\hline & Patient: $2+1+1+0$ & Patient: $2+1+1+0$ & Patient: $2+1+1+0$ \\
\hline & $\begin{array}{l}\text { Disease: } 0+3+3+1 \text { Complexity: } \\
\qquad 1+2+1+1\end{array}$ & $\begin{array}{l}\text { Disease: } 0+3+3+1 \text { Complexity: } \\
1+2+1+1\end{array}$ & $\begin{array}{l}\text { Disease: } 0+3+3+1 \text { Complexity: } \\
\qquad \begin{array}{l}1+2+1+1\end{array}\end{array}$ \\
\hline & Total: 24 & Total: 21 & Total: 18 \\
\hline \multirow{5}{*}{$\begin{array}{l}\text { (C) L3/4, L4/5, L5/S1 grade } 1 \\
\text { listhesis with stenosis ( } 3 \text { level } \\
\text { TLIF) }\end{array}$} & 3 level TLIF & 3 level TLIF & 3 level TLIF \\
\hline & Hospital: $6+1+0+0$ & Hospital: $3+1+0+0$ & Hospital: $0+1+0+0$ \\
\hline & $\begin{array}{l}\text { Patient: } 2+1+1+0 \text { Disease: } \\
0+3+3+1\end{array}$ & $\begin{array}{l}\text { Patient: } 2+1+1+0 \text { Disease: } \\
0+3+3+1\end{array}$ & $\begin{array}{l}\text { Patient: } 2+1+1+0 \text { Disease: } \\
0+3+3+1\end{array}$ \\
\hline & Complexity: $1+1+0+1$ & Complexity: $1+1+0+1$ & Complexity: $1+1+0+1$ \\
\hline & Total: 21 & Total: 18 & Total: 15 \\
\hline Case 7 & ASD without deficits & ASD without deficits & ASD without deficits \\
\hline
\end{tabular}


Table 4 (continued)

\begin{tabular}{|c|c|c|c|}
\hline Cases & Score (No shortage) & Score (No shortage) & Score (severe shortage) \\
\hline $\begin{array}{l}\text { 65-year-old Stable Adult spinal } \\
\text { deformity (ASD) }\end{array}$ & Hospital: $6+1+0+0$ & Hospital: $3+1+0+0$ & Hospital: $0+1+0+0$ \\
\hline \multirow{4}{*}{$\begin{array}{l}\text { (A) Without neurological } \\
\text { deficit }\end{array}$} & Patient: $2+1+1+0$ & Patient: $2+1+1+0$ & Patient: $2+1+1+0$ \\
\hline & Disease: $0+0+3+1$ & Disease: $0+0+3+1$ & Disease: $0+0+3+1$ \\
\hline & Complexity: $0+1+0+1$ & Complexity: $0+1+0+1$ & Complexity: $0+1+0+1$ \\
\hline & Total: 17 & Total: 14 & Total: 11 \\
\hline \multirow[t]{4}{*}{ (B) With neurological deficit } & ASD with deficits & ASD with deficits & ASD with deficits \\
\hline & $\begin{array}{l}\text { Hospital: } 6+1+0+0 \text { Patient: } \\
2+1+1+0\end{array}$ & $\begin{array}{l}\text { Hospital: } 3+1+0+0 \text { Patient: } \\
2+1+1+0\end{array}$ & $\begin{array}{l}\text { Hospital: } 0+1+0+0 \text { Patient: } \\
\qquad 2+1+1+0\end{array}$ \\
\hline & $\begin{array}{l}\text { Disease: } 0+3+6+1 \text { Complexity: } \\
0+1+0+1\end{array}$ & $\begin{array}{l}\text { Disease: } 0+3+6+1 \text { Complexity: } \\
0+1+0+1\end{array}$ & $\begin{array}{l}\text { Disease: } 0+3+6+1 \text { Complexity: } \\
0+1+0+1\end{array}$ \\
\hline & Total: 26 & Total: 20 & Total: 17 \\
\hline Case 8 & AIS 50 degrees & AIS 50 degrees & AIS 50 degrees \\
\hline \multirow{5}{*}{$\begin{array}{l}13 \text { year old } \\
\text { (A) AIS } 50 \text { degrees }\end{array}$} & Hospital: $6+2+1+0$ & Hospital: $6+2+1+0$ & Hospital: $6+2+1+0$ \\
\hline & Patient: $2+2+1+0$ & Patient: $2+2+1+0$ & Patient: $2+2+1+0$ \\
\hline & Disease: $0+0+0+0$ & Disease: $0+0+0+0$ & Disease: $0+0+0+0$ \\
\hline & Complexity: $0+0+0+1$ & Complexity: $0+0+0+1$ & Complexity: $0+0+0+1$ \\
\hline & Total: 15 & Total: 12 & Total: 9 \\
\hline \multirow[t]{6}{*}{ (B) AIS 80 degrees } & AIS 80 degrees & AIS 80 degrees & AIS 80 degrees \\
\hline & Hospital: $6+1+1+0$ & Hospital: $3+1+1+0$ & Hospital: $0+1+1+0$ \\
\hline & Patient: $2+2+1+0$ & Patient: $2+2+1+0$ & Patient: $2+2+1+0$ \\
\hline & Disease: $4+0+6+0$ & Disease: $4+0+6+0$ & Disease: $4+0+6+0$ \\
\hline & Complexity: $0+0+0+0$ & Complexity: $0+0+0+0$ & Complexity: $0+0+0+0$ \\
\hline & Total: 23 & Total: 20 & Total: 17 \\
\hline \multirow[t]{2}{*}{ Case 9} & Hospital: $6+1+1+0$ & Hospital: $3+1+1+0$ & Hospital: $0+1+1+0$ \\
\hline & Patient: $2+2+1+1$ & Patient: $2+2+1+1$ & Patient: $2+2+1+1$ \\
\hline \multirow{3}{*}{$\begin{array}{l}\text { Early onset scoliosis } 8 \text { year old, } \\
\text { Cobb angle } 40 \text { degrees }\end{array}$} & Disease: $4+0+6+0$ & Disease: $4+0+6+0$ & Disease: $4+0+6+0$ \\
\hline & Complexity: $0+1+1+0$ & Complexity: $0+1+1+0$ & Complexity: $0+1+1+0$ \\
\hline & Total: 26 & Total: 23 & Total: 20 \\
\hline
\end{tabular}

be required to validate this scoring system. Secondly, the scoring system might appear to be too complex to allow easy implementation. However, since this scoring system aims to be as objective and precise as possible, using a large 50-point-based system allows for the capability to differentiate many combinations of factors to cater to many different real-life patient scenarios.

\section{Conclusion}

In conclusion, this study is a proof of concept for the novel CCTS system to triage the priority for patients' spinal surgery and objectively match the hospital resource allocations during the COVID-19 pandemic. It is simple, objective, and allows for the otherwise complex and difficult decision to become transparent and unbiased among clinicians, hospital administrators, and patients. It matches patient care to hospital resource capacity and reduces physician burnout and moral injury. The scoring system can also be easily modified to apply to other surgical specialties. As the hospital capacity and patient factor domain remain as constant universal considerations in this pandemic, only minor changes to the disease severity and surgery complexity domains for the specific specialty are required. 


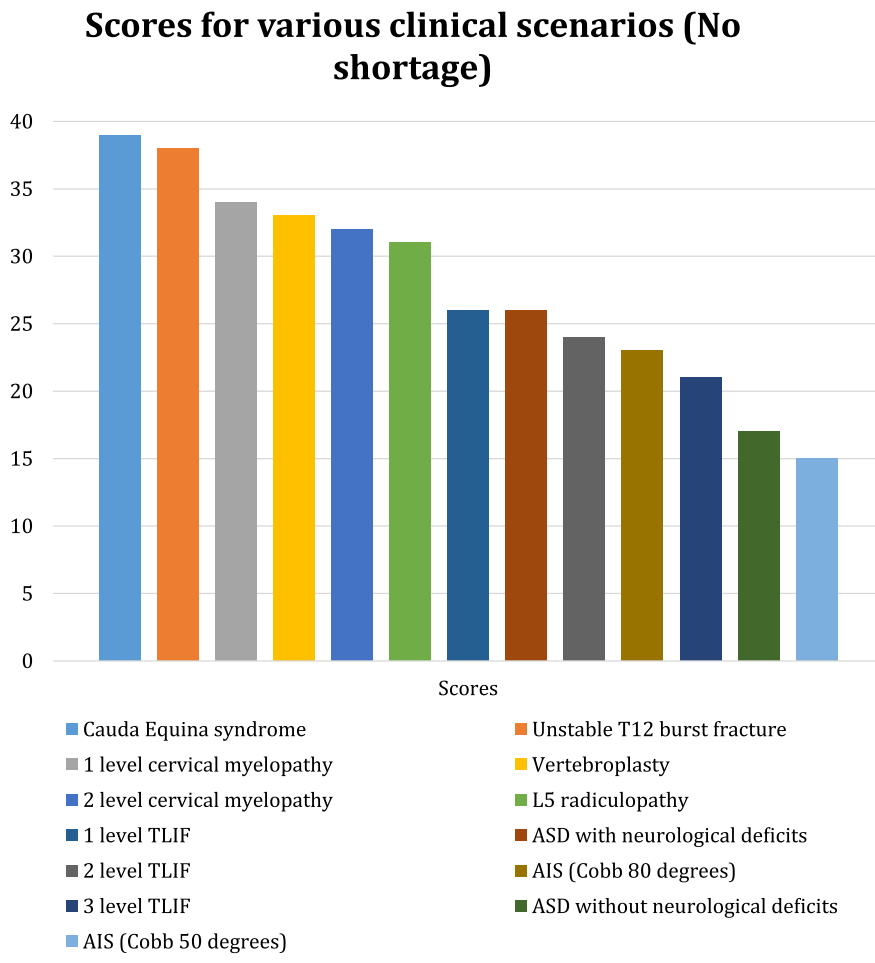

Fig. 2 Mock calculations of various clinical scenarios

Funding No funding, grant or technical support was given in the course of this study.

\section{Compliance with ethical standards}

Conflict of interest The authors declare that they have no conflict of interest.

\section{Appendix}

\section{Consensus study using the Delphi process}

After the study objectives, the structure of the scoring system, and initial parameters were determined by the lead author, the proposed system was refined using the Delphi method, spread across three rounds of analyses (Fig. 1).

In round one, the core structure of the scoring system with different domains, subdomains, and individual subdomain factors was presented to the faculties via a Webinar discussion platform. A consensus of subdomain factors for inclusion and exclusion in the scoring system was made, and the scoring system was revised. In round two, each factor of the scoring system was ranked for importance via an email survey. The faculties were instructed to rank each factor in isolation on a Likert scale of 1-10, where 1 represents the least important factor that determines the priority of surgery, and 10 indicates a maximal priority for surgery to proceed

\section{Scores for various clinical scenarios} (Moderate shortage)

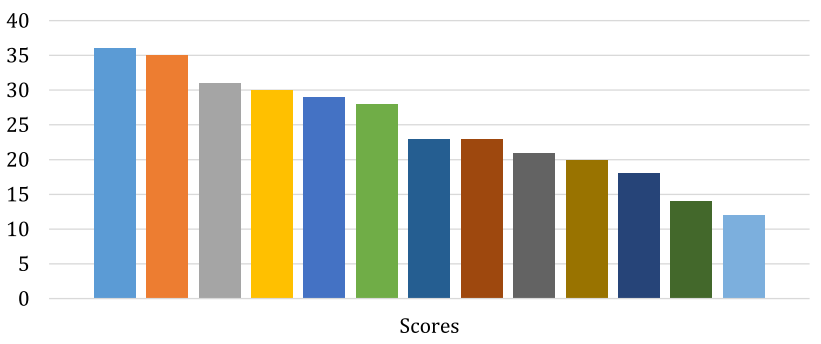

\section{Scores for various clinical scenarios} (Severe shortage)

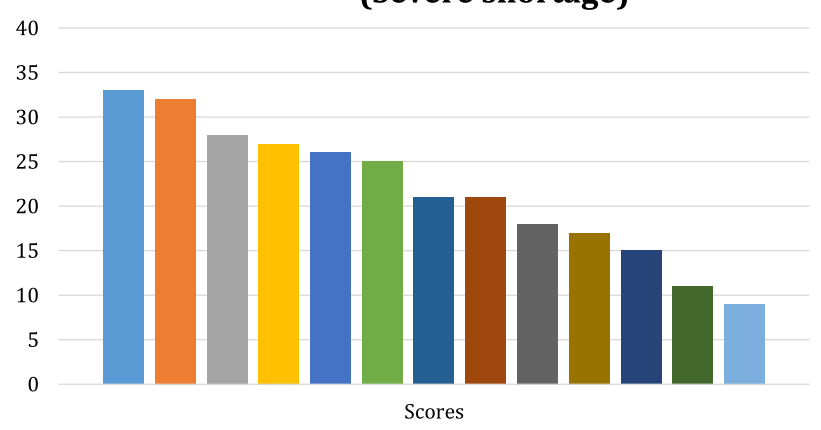

without delay. An open-text column was included for the faculties to give additional input. Each faculty was asked to complete the ranking individually, without consulting each other. The authors then calculated the mean and standard deviations of the collated responses from the faculties. Subgroup analysis by the department was performed, and the mean scores for agreement amongst the faculty were obtained. A second Webinar discussion was held with all the faculties to discuss the areas of agreement and disagreement. A consensus was reached on the priorities of surgical factors, and the domains, subdomains, and factors in the scoring system were consolidated. The final score and weightage of each factor were assigned and determined by the lead authors to meet the faculties' consensus, and guideline recommendations from $\mathrm{NHS}^{5}$, $\mathrm{NASS}^{7}, \mathrm{AAOS}^{6}$, and $\mathrm{SSS}^{8}$.

A basic score unit of 0,1 , and 2 was assigned to each factor in the subdomain. The scoring system was designed such that a higher score indicates an increased priority for surgery to proceed. A $100-300 \%$ increase in the score number was made, depending on the subdomain weightage requirement, in accordance with the $\mathrm{NASS}^{7}, \mathrm{NHS}^{5}, \mathrm{AAOS}^{6}$, and $\mathrm{SSS}^{12}$ guidelines. Calculations using the scoring system to triage hypothetical patient scenarios requiring surgeries for unstable spinal fractures with neurological deficits, cauda equina syndrome, single or multilevel cervical myelopathy, lumbar prolapsed intervertebral disc, 1-3 levels lumbar spondylolisthesis, adult and children spinal deformity were performed. 
A score range with recommendations to "defer surgery", "consider for surgery," and "proceed to list for surgery", respectively, was defined.

The third round of consensus was obtained from the survey via email correspondence. Each faculty received the revised score, a table with hypothetical patient scenarios calculations, and the proposed interpretation of the score range. The faculties were asked to indicate whether they agree or disagree with the interpretation of the proposed scoring table and score range. A consensus was defined a priori as $80 \%$ agreement across the faculties ${ }^{13}$.

\section{References}

1. Coronavirus disease 2019 (2020) (COVID-19) Situation Report - 85. World Health Organization

2. Organization WH (2020) Coronavirus disease (COVID-19) Situation Report - 154 https://www.who.int/docs/default-source/coron aviruse/situation-reports/20200622-covid-19-sitrep-154.pdf?sfvrs $\mathrm{n}=\mathrm{d} 0249 \mathrm{~d} 8 \mathrm{~d} \_2$

3. Prachand VNMR, Angelos P, Posner MC, Fung JJ, Agrawal N, Jeevanandam V, Matthews JB (2020) Medically necessary, timesensitive procedures: scoring system to ethically and efficiently manage resource scarcity and provider risk during the COVID-19 pandemic. J Am Coll Surg pii S1072(20):30317-30323. https:// doi.org/10.1016/j.jamcollsurg.2020.04.011

4. COVID-19 (2020) Recommendations for management of elective surgical procedures https://wwwfacsorg/media/files/covid19/ recommendations_for_management_of_elective_surgical_proceduresashx. Accessed May 12020

5. NHS (2020) Clinical guide for the management of patients requiring spinal surgery during the Coronavirus pandemic. https://wwwenglandnhsuk/coronavirus/wp-content/uploads/ sites/52/2020/03/specialty-guide-management-of-patients-requiring-spinal-surgery-v1-20-march-2020.pdf. Accessed May 12020

6. Guy DK, Bosco III JA, Savoie III FH (2020) AAOS Guidelines for Elective Surgery During the COVID-19 Pandemic. https://www. aaos.org/about/covid-19-information-for-our-members/aaos-guide lines-for-elective-surgery. Accessed 4 Dec 2020

7. NASS (2020) NASS Guidance document on Elective, Emergent and Urgent Spine Procedures and Treatments https://wwwspineorg/Portals/0/assets/downloads/Publications/NASSInsider/NASSGuidanceDocument040320.pdf. Accessed April 242020

8. Tan KA, Thadani VN, Chan D, Oh JYL, Liu GKP (2020) Addressing coronavirus disease 2019 in spine surgery: a rapid national consensus using the Delphi Method via teleconference. Asian Spine J. https://doi.org/10.31616/asj.2020.0224

9. Pratik H, Khedkar AP (2020) SARS-CoV-2: what do we know so far? Acta Physiol (Oxf) 229:e13470

10. Schmidt RC (1997) Managing Delphi surveys using nonparametric statistical techniques. Decis Sci 28:763-774

11. Hsu CCSB (2012) The Delphi technique use, consideration, and applications in the conventional, policy, and on-line environments. In: Silva CN (ed) Online research methods in urban and planning studies design and outcomes Hershey. IGI, PA

12. Knuf KMMC, Cummings AK (2018) Clinical agreement in the American Society of Anesthesiologists physical status classification. Perioper Med (Lond) 7(1):1-6

13. Boonstra AMSPH, Balk GA, Stewart RE (2014) Cut-off points for mild, moderate, and severe pain on the visual analogue scale for pain in patients with chronic musculoskeletal pain. Pain 155:2545-2550

14. Vaccaro ARLRJ, Hurlbert RJ, Anderson PA, Harris M, Hedlund R, Harrop J, Dvorak M, Wood K, Fehlings MG, Fisher C, Zeiller SC, Anderson DG, Bono CM, Stock GH, Brown AK, Kuklo T, Oner FC (2005) A new classification of thoracolumbar injuries: the importance of injury morphology, the integrity of the posterior ligamentous complex, and neurologic status. (Spine Phila $\mathrm{Pa}$ 1976) 30:2325-2333

15. Association ASI Worksheet International standards for neurological classification of spinal cord injury (ISNCSCI). https:// asia-spinalinjuryorg/wp-content/uploads/2016/02/International_ Stds_Diagram_Worksheet.pdf. Accessed June 92020

16. Yonenobu KAK, Nagata K, Taketomi E, Ueyama K (2001) Interobserver and intraobserver reliability of the Japanese orthopaedic association scoring system for evaluation of cervical compression myelopathy. (Spine Phila Pa 1976) 26:890-894

17. Fisher CGDC, Ryken TC, Bilsky MH, Shaffrey CI, Berven SH, Harrop JS, Fehlings MG, Boriani S, Chou D, Schmidt MH, Polly DW, Biagini R, Burch S, Dekutoski MB, Ganju A, Gerszten PC, Gokaslan ZL, Groff MW, Liebsch NJ, Mendel E, Okuno SH, Patel S, Rhines LD, Rose PS, Sciubba DM, Sundaresan N, Tomita K, Varga PP, Vialle LR, Vrionis FD, Yamada Y, Fourney DR (2010) A novel classification system for spinal instability in neoplastic disease: an evidence-based approach and expert consensus from the spine oncology study group. (Spine Phila Pa 1976) 35:1221-1229

18. Kato STK, Matsudaira K, Tonosu J, Hara N, Chikuda H (2012) Normative score and cut-off value of the neck disability index. J Orthop Sci 17:687-693

19. Tonosu JTK, Hara N, Matsudaira K, Kato S, Masuda K, Chikuda $H$ (2012) The normative score and the cut-off value of the oswestry disability index (ODI). Eur Spine J 21:1596-1602

20. Scott Yang LMA, Redding GJ, Skaggs DL (2015) Early-onset scoliosis: a review of history, current treatment, and future directions. Pediatrics 137:e20150709. https://doi.org/10.1542/ peds.2015-0709

21. Helenius IJ (2018) Treatment strategies for early-onset scoliosis. EFORT Open Rev 3:287-293

22. Kenyon C (2020) Flattening-the-curve associated with reduced COVID-19 case fatality rates- an ecological analysis of 65 countries. J Infect Pii S0163(20):30215-30222. https://doi. org/10.1016/j.jinf.2020.04.007

23. Anderson RMHH, Klinkenberg D, Hollingsworth TD (2020) (2020) How will country-based mitigation measures influence the course of the COVID-19 epidemic? Lancet 395(10228):931-934

24. Zhang ZYW, Wang Y, Long C, Fu X (2020) Wuhan and Hubei COVID-19 mortality analysis reveals the critical role of timely supply of medical resources. J Infect 81:147. https://doi. org/10.1016/j.jinf.2020.03.018

25. Leung KWJT, Liu D, Leung GM (2020) First-wave COVID19 transmissibility and severity in China outside Hubei after control measures, and second-wave scenario planning: a modelling impact assessment. Lancet. https://doi.org/10.1016/S0140 $-6736(20) 30746-7$

26. Rosenbaum L (2020) Facing Covid-19 in Italy - ethics, logistics, and therapeutics on the epidemic's front line. N Engl J Med. https://doi.org/10.1056/NEJMp2005492

27. Lin CYPY, Wu YH, Chang J, Chan CH, Yang DY (2007) The psychological effect of severe acute respiratory syndrome on emergency department staff. Emerg Med J 24:12-17

28. Osmers I (2017) Orthopedic surgery with limited resources after mass disasters and during armed conflicts: first international guidelines for the management of limb injuries and the experience of doctors without borders. Unfallchirurg 120:815-822 
29. Jiménez-Ávila JMA, Sanchez-Garcia O, González-Cisneros AC (2019) Guidelines in the decision of surgical management in spine surgery. Cir Cir 87:299-307

30. Riccioni LBG, Giannini A, Vergano M, Gristina G, Livigni S, Mistraletti G (2020) Petrini gruppo di lavoro siaarti-società italiana di anestesia analgesia rianimazione e terapia intensiva $\mathrm{f}$ clinical ethics recommendations for the allocation of intensive care treatments, in exceptional, resource-limited circumstances. Recenti Prog Med 111:207-211

31. Litton EBT, Chavan S, Ho YY, Holley A, Howard G, Huckson S, Kwong P, Millar J, Nguyen N, Secombe P, Ziegenfuss M, Pilcher D (2020) Surge capacity of intensive care units in case of acute increase in demand caused by COVID-19 in Australia. Med J Aust. https://doi.org/10.5694/mja2.50596

32. Badiee RKMR, Pennicooke B, Chou D, Mummaneni PV, Tan LA (2020) Complications following posterior cervical decompression and fusion: a review of incidence, risk factors, and prevention strategies. J Spine Surg 6:323-333

33. Dial BLEV, Danilkowicz R, O'Donnell J, Sugarman B, Blizzard DJ, Erickson ME (2020) Factors associated with extended length of stay and 90-day readmission rates following ACDF. Global Spine J 10:252-260

34. Schilling ATEJ, Huq S, Ahmed AK, Lubelski D, Cottrill E, Pennington Z, Shin JH, Sciubba DM (2020) Risk factors for wound-related complications following surgery for primary and metastatic spine tumors: a systematic review and metaanalysis. World Neurosurg pii S1878(20):30681-30691. https ://doi.org/10.1016/j.wneu.2020.03.210

35. Ilyas HGJ, Chen J, Winkelman RD, Mroz TE, Steinmetz MP (2019) Risk factors for 90-day reoperation and readmission after lumbar surgery for lumbar spinal stenosis. J Neurosurg Spine $31: 20-26$
36. Sulaiman Somani JDC, Kim JS, Phan K, Lee NJ, Kothari P, Kim J-H, Dowdell J, Cho SK (2017) ASA classification as a risk stratification tool in adult spinal deformity surgery: a study of 5805 patients. Global Spine J 7:719-726

37. Ryu JHKT, Ha JY, Jung MR, Ha JW, Yang J (2018) Factors associated with waiting time to deceased donor kidney transplantation in transplant candidates. Transplant Proc 50:1041-1044

38. López IPRA, Bastante MD, Herrera TV, Gómez EB, Becerra Massare A, Villar Del Moral JM (2020) How can we improve the selection of patients awaiting liver retransplantation? Transplant Proc 52:534-536

39. Pekka Kuittinen PS, Saari T, Aalto TJ, Sinikallio S, Savolainen S, Kröger H, Turunen V, Leinonen V, Airaksinen O (2014) Visually assessed severity of lumbar spinal canal stenosis is paradoxically associated with leg pain and objective walking ability. BMC Musculoskelet Disord 15:348

40. Gregory D, Schroeder MFK, Vaccaro AR (2016) Lumbar spinal stenosis: how is it classified? J Am Acad Orthop Surg 24:843-852

41. Antònia Matamalas MR, Mojal S, García De Frutos A, Molina A, Saló G, Lladó A, Cáceres E (2010) The visual analog scale and a five-item verbal rating scale are not interchangeable for back pain assessment in lumbar spine disorders. (Spine Phila Pa 1976) 35:E1115-1119

42. Horn SRLT, Horowitz JA, Oh C, Bortz CA (2018) Clinical impact and economic burden of hospital-acquired conditions following common surgical procedures. (Spine Phila Pa 1976) 43:E1358-E1363

43. Yu-Kun He H-ZL, Hua-Ding Lu (2019) Is blood transfusion associated with an increased risk of infection among spine surgery patients?: a meta-analysis. Med (Baltimore) 92:e16287

Publisher's Note Springer Nature remains neutral with regard to jurisdictional claims in published maps and institutional affiliations.

\section{Affiliations}

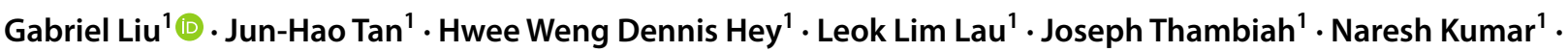 Jonathan Tan ${ }^{1}$. John Ruiz ${ }^{1}$. Vincent Nga ${ }^{1}$. Sein Lwin ${ }^{1} \cdot$ Kejia Teo $^{1}$. Chou Ning ${ }^{1} \cdot$ Rohit Vijay Agrawal ${ }^{1} \cdot$ Bryan NG $^{1}$. Weng Hoa Wong ${ }^{1} \cdot$ Tseng Tsai Yeo $^{1} \cdot$ Hee-Kit Wong ${ }^{1}$}

Jun-Hao Tan

junhao_tan@nuhs.edu.sg

Hwee Weng Dennis Hey

hwee_weng_hey@nuhs.edu.sg

Leok Lim Lau

leok_lim_lau@nuhs.edu.sg

Joseph Thambiah

Joseph_THAMBIAH@nuhs.edu.sg

Naresh Kumar

Naresh_Kumar@nuhs.edu.sg

Jonathan Tan

jonathan_jh_tan@nuhs.edu.sg

John Ruiz

John_Nathaniel_RUIZ@nuhs.edu.sg

Vincent Nga

vincent_nga@nuhs.edu.sg

Sein Lwin

sein_lwin@nuhs.edu.sg
Kejia Teo

kejia_teo@nuhs.edu.sg

Chou Ning

ning_chou@nuhs.edu.sg

Rohit Vijay Agrawal

rohit_agrawal@nuhs.edu.sg

Bryan NG

bryan_ng@nuhs.edu.sg

Weng Hoa Wong

anawwh@nus.edu.sg

Tseng Tsai Yeo

tseng_tsai_yeo@nuhs.edu.sg

Hee-Kit Wong

heekit_wong@nuhs.edu.sg

Department of Orthopaedic Surgery, University Spine Centre, National University Hospital, National University Health System, 1E Kent Ridge Road, Singapore 119228, Singapore 